\title{
Study on parturition of beef cattle in small holder farm: stage, placental weight, and placentomes
}

\author{
Sri Gustari ${ }^{1 *}$, Surya Agus Prihatno ${ }^{1}$, Asmarani Kusumawati $^{1}$, Agung Budiyanto ${ }^{1}$, Erif \\ Maha Nugraha Setyawan ${ }^{1}$, Yosua Kristian Adi ${ }^{1}$, Topas Wicaksono Priyo $\mathrm{Jr}^{1}$, \\ ${ }^{1}$ Department of Reproduction and Obstetric, Faculty of Veterinary Medicine, Universitas Gadjah \\ Mada, Indonesia 55281
}

\begin{abstract}
Scientific data on the length of parturition stage, placental weight, and the number of placentomes in Ongole (PO), Simental Ongole (SimPO), Limosin and Ongole (LimPO) breeds in Yogyakarta Province are not yet known. This research aimed to study parturition stage, placental weight, and placentomes number on beef catlle in small holder farm. This research was carried out on small farmers in the Special Region of Yogyakarta Province. There were 22 PO, 7 simpo, and 4 limpo cattle. The first study determined length stage of parturition. The second study determined the weight of the placenta and the number of placentomes. Data collected were analyzed descriptively. The results of first stage in PO, SimPO, and LimPO cattle were 73.7, 44.5, and 62.9 hours. The duration of second stage in PO, SimPO, and LimPO cattles were 58.1, 78.7, and 24.5 minutes. The duration of third stage in PO, SimPO, and LimPO cattle were 4.3, 4.8, and 3.5 hours. The placenta weight in PO and SimPO cattle showed that the average of placenta weight was 4.1 and $3.6 \mathrm{Kg}$. The number of placentomes in PO, SimPO, dan LimPO cattle were 92.5, 92.8, and 102.6. This research showed that the average of stage I in PO was longer than SimPO and LimPO, stage II and stage III in SimPO was longer than PO and LimPO. In addition, the average of placenta weight in PO was heavier than SimPO and LimPO cows. The average number of placentomes in LimPO was higher than PO and SimPO cattle.
\end{abstract}

\section{Introduction}

Reproduction cycles are started from puberty, oestrus, mating, gestation and parturition process. Parturition is a physiological process when the utery release its fetus and placenta form the body. Reproduction cycles are started from puberty, oestrus, mating, gestation and parturition process. Parturition is a physiological process when the utery release its fetus and placenta form the body. Symptoms that may occurs before due date was the change of mammary gland development and relaxation of the pelvic ligaments but these symptoms are very high variable and inconsistent and cannot be used precision delivery [15]. These

\footnotetext{
*Corresponding author: gustari_vet@ugm.ac.id
} 
symptoms are very useful as an aid in marking the presence of parturition, but these symptoms vary widely and cannot be used to predict the day of delivery [1]. Parturition is divided into 3 stages, namely stage one cervical dilation, stage two fetal expulsion, and stage three placental expulsion [2 and 3]. The time required for stage one is between 6-12 hours. Stage two fetal expulsion lasts 2-4 hours, if more indicates dystocia [2], Stage 3 lasts between 6 to 12 hours [3].

The placenta is often called the fetal membrane which is composed of amniotic membranes, allantois and chorionallantois. Each layer of the placenta has its own role and function. The placenta consists of the parent placenta (caruncle) and fetal placenta (cotyledons). The joining of the mother placenta and fetus placenta is called placentome. In animals, the number of placentomes and weight of the placenta in each species is different. The number of placentoms in cows ranges from 70-120 pieces [4]. The number of placentomes in dairy cows with first and second calves ranged from 47 to 134 and 60 to 131 fruits, respectively, with placental weights of about $3.7 \pm 1.0 \mathrm{~kg}$ and $3.1 \pm 1.0 \mathrm{~kg}$ [5]. While the Swedish red and white breed dairy cows, the number of placemtomes in cows with first and second calves ranged from 40-114 and 41-103, respectively, with placental weights of about $3.3 \pm 0.7 \mathrm{~kg}$ and $3.0 \pm 0.8 \mathrm{~kg}$ [14].

Scientific data on the length of parturition stage, placental weight, and the number of placentomes in Ongole (PO) beef cattle, Simental Ongole (SimPO), and Limosin Ongole (LimPO) breeds in Yogyakarta Province are not yet known. This research aimed to study parturition stage, placental weight, and placentomes number on beef catlle in small holder farm. The results of this study are expected to provide an overview and become a reference for reproductive science regarding the length of the stage of labor, the number of placentomes and the weight of the placenta in PO, SimPO, LimPO cattle on smallholder farms.

\section{Materials and methods}

The research was a field study that carried out on various breed of beef cows. The cows were at least in 9 months of pregnancy. Observation was done for 24 hours everyday to monitore parturition sign of each stadium until parturition has completed. This research was carried out on small farmers in the Special Region of Yogyakarta Province. There were 32 beef cows participating in this research, consisted of 22 PO, 7 SimPO, and 4 LimPO cattle. This research is divided into two. The first study determined stage length of parturition. The second study determined the weight of the placenta and the number of placentomes. Data collected were duration of each stadium, placenta weight, also the number of placentomes, then analyzed descriptively.

\section{Results and Discussions}

The results of stadium parturition were described in Table 1. The duration of first stadium in PO, SimPO, and LimPO cattle were 73.7, 44.5, and 62. 9 hours, respectively. The duration of second stadium in PO, SimPO, and LimPO cattles were 58.1, 78.7, and 24.5 minutes respectively. The duration of third stadium in PO, SimPO, and LimPO cattle were 4.3, 4.8, and 3.5 hours respectively. 
Table 1. The average times of parturition stages of PO, SimPO and LimPO cattle in Yogyakarta Province.

\begin{tabular}{cccc}
\hline & $\begin{array}{c}\text { Stadium I } \\
\text { (hours) }\end{array}$ & $\begin{array}{c}\text { Stadium II } \\
\text { (minutes) }\end{array}$ & $\begin{array}{c}\text { Stadium III } \\
\text { (hours) }\end{array}$ \\
\hline PO & 73.7 & 58.1 & 4.3 \\
SimPO & 44.5 & 78.7 & 4.8 \\
LimPO & 62.9 & 24.5 & 3.5 \\
\hline
\end{tabular}

Our results were not in agreement with previous findings which was first stadium of parturition take about 6-12 hours [2], 2-6 hours [3], 28.5 hours [6]. In contrast with our results, the average time of stadium II of parturition was 120-360 minutes [2], 30-60 minutes [3], 17 minutes [7]. Our findings were also different with previous study, stadium III of parturition usually take 30 minutes - 8 hours [2], 6-12 hours [3], and $6-8$ hours [7]. The factors that may affect the stadium of parturition were physical factor, hormones, nutrition, and breed. Fetal size was included as physical factors. The hormonal factors were the increasing of estrogen hormone, decreasing of progesterone hormone, increasing of prostaglandin, oxytocin, and relaxin hormones. Nutrition intake such as protein, fat, carbohydrate and mineral are affecting uterus contraction during parturition $[7 ; 8 ; 9 ; 10]$.

The results of placenta weight and the number of placentome in PO, SimPO, and LimPO were shown in Table 2. In PO and SimPO cattle showed that the average of placenta weight was 4.1 and $3.6 \mathrm{Kg}$. In addition, the number of placentome in PO, SimPO, dan LimPO cattle were $92.5,92.8$, and 102.6, respectively.

Table 2. The averages of placenta weight and placentome of PO, SimPO, and LimPO cattle in Yogyakarta Province

\begin{tabular}{ccc}
\hline & $\begin{array}{c}\text { Placenta } \\
\text { weight }(\mathrm{kg})\end{array}$ & Placentome $(\mathrm{n})$ \\
\hline PO & 4.1 & 92.5 \\
SimPO & 3.6 & 92.8 \\
LimPO & & 102.6 \\
\hline
\end{tabular}

Although the averages of placenta weight in SimPO parent were lower than PO, the average of calve weight of SimPO dan LimPO were heavier than PO. Averages of placentome number in SimPO and LimPO which maintained in local farm in Yogyakarta province was higher than PO cattle. Several literature states that the weight of fetal membranes 4,9-5,2 kg. Breed and parity were play in role of affecting placental weight. As transport of nutrients and waste takes place at the functional sites of the placentomes, the membranes do not have an active role in supplying nutrients toward the calf [13].

Several literature states that the variety number of placentomes in cattle were 70-120 pieces [4], 75-120 pieces [2], and 120 pieces [7]. 51-211 pieces [13]. Breed and nutrition were play in role of affecting the number and placentome shapes. Research evidence shows that there is a change in placentome conformation in ruminants in response to changes in nutritional intake so that fetal development is maintained normally [7]. Since during pregnancy, all uteri have spare caruncles not covered or attached to a cotyledon it seems that the number of the buttons that will be used during pregnancy to contribute in the nutrition of the fetus and hence develop toward active placentomes, may be regulated by several factors. Furthermore, in cattle, placentome number is known to be established early in gestation and to not change throughout pregnancy [13].

In other ruminants, namely sheep, nutritional intake at the beginning and middle of pregnancy greatly affects the number, size and shape of placentomes. If nutrition at the 
beginning and middle of pregnancy is lacking, the number of placentomes will decrease but their size and shape will increase [11]. It has been confirmed that nutrition intake affected the placentome number in sheep [12] and cattle [13].

\section{Conclusion}

The average of stadium I parturition in PO was longer than SimPO and LimPO, meanwhile the average of stadium II and stadium III parturition in SimPO was longer than PO and LimPO. In addition, the average of placenta weight in PO was heavier than SimPO and LimPO cows. The average number of placentome in LimPO was higher than PO and SimPO cattle.

\section{References}

1. M.R. Jaenudin, E.S.E. Hafez, Gestation, Prenatal Physiology and Parturition. In Reproduction in Farm Animals 5th Ed. (Lea \& Febiger, Philadelphia, 1987)

2. S.J. Roberts, Veterinary Obstetrics and Genital Diseases (Theriogenology) (Woodstock, Vermont, 1986).

3. M.R. Jaenudin, E.S.E. Hafez, Gestation, Prenatal Physiology and Parturition in Reproduction Farm Animals 7th Ed. (Lippincot, William \& Wilkins, Philadelphia, 2000)

4. Senger, Pathways to Pregnancy and Parturition (Washington State University, Washington, 2003)

5. B. Kornmatitsuk, K. Königsson, H. Kindahl, H. Gustafsson, M. Forsberg, A. Madej, J. Vet. Med. A 47, 395-409 (2000)

6. V.N.A. Breeveld-Dwarkasing, P.C. Struijk, F. Eijskoot, F.K. Lotgering, M.A.M. Taverne, Therio. 57, 1989-2002 (2002)

7. D.E. Noakes, T.J. Parkinson, G.C.W, Veterinary Reproduction and Obstetrics $9^{\text {th }}$ Edition (Elsevier, London, 2010)

8. R.P. Waterman, Precalving Nutrition/birth Weight Interaction and Rebreeding Efficiency. Proceedings, The Range Beef Cow Symposium XIII: 214 (1993)

9. R.N. Funston, D.M. Larson, Vonnahme, J. Anim. Sci. 88, 205-215 (2010)

10. A.H.A. Safdar, N.M. Kor, Eur. J. Exp. Bio 4, 211-218 (2014)

11. J.L. Black, Growth and development of lambs. (Easter School Proceedings, Nottingham, 1983)

12. G.J. Faichney, Proc. Nutr. Soc. Austr 6 (1981)

13. V. Eetvelde, M. Kamal, M. Hostens, M. Vandaele, L. Fiems, G. Opsomer, Animal 8, 1342-1350 (2016).

14. B. Kornmatitsuk, G. Franzen, H. Gustafsson, H. Kindahl, Acta Vet. Scand. 44, 21-33 (2003)

15. C. Nagel, J. Aurich, C. Aurich, C. 2020. Theriogenology. 150. 308-312 (2020) 